\title{
Flow in the time of COVID-19: Findings from China
}

\author{
Kate Sweeny ${ }^{1 *}$, Kyla Rankin ${ }^{1}$, Xiaorong Cheng ${ }^{2}$, Lulu Hou ${ }^{3}$, Fangfang Long ${ }^{3}$, \\ Yao Meng ${ }^{3}$, Lilian Azer ${ }^{1}$, Renlai Zhou ${ }^{3 *}$, Weiwei Zhang ${ }^{1}$ \\ 1 Department of Psychology, University of California, Riverside, California, United States of America, \\ 2 School of Psychology, Central China Normal University, Wuhan, China, 3 Department of Psychology, \\ Nanjing University, Nanjing, China \\ * ksweeny@ucr.edu (KS); rlzhou@ nju.edu.cn (RZ)
}

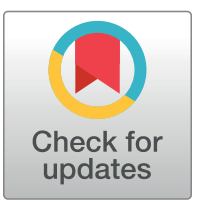

\section{openaccess}

Citation: Sweeny K, Rankin K, Cheng X, Hou L, Long F, Meng Y, et al. (2020) Flow in the time of COVID-19: Findings from China. PLOS ONE 15(11): e0242043. https://doi.org/10.1371/journal. pone. 0242043

Editor: Natalie J. Shook, University of Connecticut, UNITED STATES

Received: June 11, 2020

Accepted: October 26, 2020

Published: November 11, 2020

Copyright: ๑ 2020 Sweeny et al. This is an open access article distributed under the terms of the Creative Commons Attribution License, which permits unrestricted use, distribution, and reproduction in any medium, provided the original author and source are credited.

Data Availability Statement: Deidentified data are available on the Open Science Framework (https:// osf.io/vuwg3/).

Funding: The authors received no specific funding for this work.

Competing interests: The authors have declared that no competing interests exist.

\section{Abstract}

In February 2020, the Novel Coronavirus (COVID-19) was raging in Wuhan, China and quickly spreading to the rest of the world. This period was fraught with uncertainty for those in the affected areas. The present investigation examined the role of two potential coping resources during this stressful period of uncertainty: flow and mindfulness. Participants in Wuhan and other major cities affected by COVID-19 $(N=5115)$ completed an online survey assessing subjective experiences of flow, mindfulness, and well-being. Longer quarantine was associated with poorer well-being; flow and mindfulness were associated with better well-being on some measures. However, flow—but not mindfulness-moderated the link between quarantine length and well-being, such that people who experienced high levels flow showed little or no association between quarantine length and poorer well-being. These findings suggest that experiencing flow (typically by engaging in flow-inducing activities) may be a particularly effective way to protect against potentially deleterious effects of a period of quarantine.

\section{Introduction}

According to the World Health Organization (WHO), nearly 36.3 million people are currently confirmed to have Novel Coronavirus (2019-nCoV, or COVID-19) at the time of writing in October 2020. COVID-19, which is deceptively similar to pneumonia and influenza, has impacted healthcare, shifted the political climate, and created a financial crisis. New areas of the world report cases daily, some level of quarantine or social distancing is recommended (if not required) where the virus is present, and on March 11, 2020 the WHO officially identified COVID-19 as a pandemic. Social distancing efforts seek to decrease the number of people in contact with one another with the goal of minimizing the spread of infection. As a more drastic measure, quarantine involves complete isolation, with recommendations directing people testing positive or showing symptoms of COVID-19 to quarantine for 14 days. The present investigation seeks to identify effective strategies for managing distress during this stressful period of worldwide uncertainty, particularly among those facing the psychological challenges of quarantine conditions in Wuhan, China and other affected Chinese cities in February 2020. 


\section{COVID-19 in Wuhan, China}

The first case of COVID-19 was detected in Wuhan, China and reported to the WHO China Country Office on December 31, 2019. At the time, the nature, cause, and means of transmission of COVID-19 remained unclear. With the first exported cases reported in Thailand, Japan, and South Korea in mid-January, the Chinese government chose to take action by imposing an emergency lockdown beginning on January 23, 2020, requiring people to remain in the area and self-quarantine. In response to the quickly-spreading virus, many governments around the world followed by recommending, some even mandating, social distancing or quarantine measures.

The spread of this virus has created massive disruption in people's lives and enormous amounts of uncertainty: Schools are closed or transitioned online, jobs are either substantially reimagined or eliminated altogether, people are testing positive for the virus without showing symptoms, and knowing when the containment of COVID-19 will bring normalcy is impossible. While people wait to see how the virus progresses and when vaccines will become available, physical distancing and self-quarantining are encouraged, if not required, for many.

Research assessing the psychological effects of quarantine-like conditions during previous virus outbreaks (e.g., Severe Acute Respiratory Syndrome, Ebola Virus Disease, and Influenza A virus subtype H1N1) identified several key sources of distress: fear of infection for self and others, inadequate information from health authorities, feelings of frustration and boredom, and, most relevant to the current investigation, quarantine length [1]. Specifically, longer quarantine durations predicted greater post-traumatic stress disorder symptomology [2,3] and greater emotional exhaustion and distress in healthcare workers [4], and the current lockdown in France for COVID-19 was associated with slowing down of time, seemingly driven by boredom and sadness [5]. Given the negative consequences of increased quarantine length, how can people hold their rising distress at bay in ways that reduce boredom and frustration as quarantine conditions persist and concerns about the impact of the virus grow?

\section{Harnessing flow and mindfulness while coping with uncertainty}

Two promising candidates for effective coping during the COVID-19 pandemic are flow and mindfulness. Flow is a state in which people become absorbed in an enjoyable activity, such that they become blind to their external environment and unconcerned about the self or the passage of time [6]. To reach a flow state, people must engage in an intrinsically rewarding activity that is just challenging enough to match one's skill level and that provides clear goals and feedback. A large body of evidence links flow to greater well-being in a variety of domains, including work [7, 8], sports [9], collective gatherings and rituals [10], and general leisure activities [11]. Most relevant to this study, flow is effective for boosting emotional well-being during stressful periods of uncertainty [12]. Notably, researchers have documented the benefits of flow across a number of cultures and countries, including Japan [13, 14], Czech Republic [15], Hong Kong [16], Sweden [17], and Italy [18].

In contrast to flow states, mindfulness is a state of being aware of and attentive to one's current internal and external experience, focusing on the present moment and observing without judgment [19]. Traditionally a Buddhist teaching, mindfulness has become an asset to medicine, healthcare, and psychology [20-24]. As with flow, a large body of evidence links mindfulness to greater well-being, including lower depression and anxiety [21], less psychological distress and invasive negative thoughts [25], and more positive thinking [26]. A meta-analysis of 163 studies $(d=.28)$ confirmed that practicing mindfulness meditation is associated with greater well-being on a number of metrics [27]. Most relevant to the current investigation study, mindfulness promotes effective coping during periods of acute uncertainty [28]. 
Flow and mindfulness are similar in that they both involve focused attention on the present moment. They are also both accessible via active engagement in specific activities-that is, one does not have to be a particular kind of person to experience flow or mindfulness [e.g., flow: 29, 30; mindfulness: 31, 32]. However, they differ in important ways. Most notably, flow reduces self-awareness and awareness of one's external environment, whereas mindfulness draws one's attention to internal and external experiences $[6,24,33]$. In fact, experimental work has shown that flow and mindfulness are antithetical. When people practice mindfulness prior to engaging in a flow-inducing activity, they report feeling less absorbed in the activity [34].

The current investigation compares associations between flow and mindfulness on the one hand and well-being on the other during a period of stressful uncertainty, specifically the rise of COVID-19 in Wuhan and other affected cities in China. We hypothesized that a longer quarantine would be associated with poorer well-being and that flow and mindfulness would be associated with greater well-being overall during this period. We further hypothesized that flow and mindfulness may play different roles in mitigating the deleterious effects of quarantine length on well-being. Because flow states reduce self-awareness and speed the apparent passage of time (i.e., time "flies by"), we anticipated that it may be particularly effective for reducing the impact of longer quarantines on well-being. Given that our study assessed selfreported flow and mindfulness (i.e., no experimental intervention), our specific hypothesis is that flow will consistently moderate associations between quarantine status and various measures of well-being. We did not have a strong a priori prediction about the moderating role of mindfulness.

\section{Method}

\section{Participants and procedure}

This study (\#NJUPSY202002002) was approved by the Ethics Committee of Nanjing University, and consent was obtained via an online document (participants clicked "continue" if they consented to participate in the survey). Participants in China $(N=5115$; see Table 1 for demographic information) were recruited online between February 12-19, 2020. We recruited as many participants as possible during the relevant period of time. We did not conduct a power

Table 1. Demographic information.

\begin{tabular}{l|c}
\hline Sample Characteristics & $(\mathbf{N} \mathbf{5 1 5})$ \\
\hline$\%$ female & $72.8 \%$ \\
\hline Mean age & $21.36(S D=4.39)$ \\
\hline Education & $0.3 \%$ \\
\hline Did not complete high school & $1.2 \%$ \\
\hline Completed high school only & $95.9 \%$ \\
\hline Completed college $(2$ - or 4 -year degree) & $3.5 \%$ \\
\hline Completed Master's degree & $28 \%$ \\
\hline At least 1 sibling & \\
\hline Family income & $50.8 \%$ \\
\hline Less than $\$ 50,000$ & $31.3 \%$ \\
\hline$\$ 50,000-\$ 100,000$ & $11.2 \%$ \\
\hline$\$ 100,000-\$ 200,000$ & $3.1 \%$ \\
\hline$\$ 200,000-\$ 300,000$ & $3.7 \%$ \\
\hline Above $\$ 300,000$ & \\
\hline
\end{tabular}

https://doi.org/10.1371/journal.pone.0242043.t001 
analysis; however, our sample size is more than sufficient for the relevant analyses at nearly any effect size.

The online survey was hosted on IQEQ (Intelligence Quotient and Emotional Quotient), a dedicated online research platform with a mobile-friendly interface for smartphones and tablets, which was developed by one of the co-authors (R.Z.) at Nanjin University. Participant recruitment was targeted at college students via social media (WeChat platform). No course credit or monetary reward was offered for participants. The survey took participants an average of 9 minutes to complete.

\section{Measures}

Due to the challenging context in which this study was conducted, we were only able to survey our participants once. Thus, our primary measures asked participants to respond based on their experiences "in the past week" in an effort to capture general experiences during that period of time rather than experiences on what could have been an idiosyncratic day. Similarly, we were only able to contact participants remotely (i.e., online), and thus we relied on selfreport measures as objective observational measures were infeasible. All scales, originally in English, were translated into Chinese by three co-authors (X.C., R.Z., and W.Z.). Specifically, X.C. and R.Z. translated the scales independently, and W.Z. then verified and combined the translations. The high degree of internal reliability achieved for all of the scales provide reassurance that this translation process was successful.

Flow and mindfulness. Flow experienced during the past week was assessed using the five-item Short Flow Scale [6, 12, 35, 36] ("I felt very interested in what I was doing," "I felt unaware of myself; I was only aware of the tasks at hand," "I felt very absorbed in what I was doing," "I felt that there was no separation between me and my behavior," and "I felt very stimulated and challenged"; $1=$ not at all, $7=$ very much; $M=4.37, S D=1.13$, Cronbach's $\alpha=.80$ ). Although this scale has not undergone formal validation, several studies have confirmed its association with positive emotions $[12,36]$, as well as negative associations with negative emotions and worry during periods of stressful uncertainty [12].

Mindfulness experienced during the past week was assessed using the 12-item Cognitive and Affective Mindfulness Scale-Revised [37] (e.g., "It is easy for me to concentrate on what I am doing," "I try to notice my thoughts without judging them"; $1=$ rarely $/$ not at all, $4=$ almost always; $M=2.50 ; S D=.47, \alpha=.75)$. This measure has undergone extensive validation [37], including in China [38]. The correlation between flow and mindfulness was quite strong, $r(5115)$ $=.56, p<.0001$, although not so strong as to suggest that they represent the same construct.

Quarantine length. Quarantine length was coded as follows: $1=0$ days (not yet quarantined; $74 \%$ of the sample), $2=1-7$ days ( $2 \%), 3=7-14$ days $(6 \%)$, and $4=$ more than 14 days $(18 \%)$. Because the measure was positively skewed, we log-10 transformed it. Although the variable was still skewed after transformation (skewness $=1.16$ ), skewness was notably reduced. Note that quarantine in China was largely mandatory and quite strict, not optional or loosely defined as it is for most people in the United States.

Worry and emotions. We assessed worry using three items adapted from the McCaul Brief Worry Scale, standardizing each item before averaging due to differing scaling across items [39] (e.g., "How worried are you about the coronavirus?;" $1=$ not at all, $5=$ extremely; $M$ $=-.0003 ; S D=.85, \alpha=.81)$. Emotions were assessed with the Scale of Positive and Negative Experience [40] ( $1=$ very rarely or never, $5=$ very often or always $)$; specifically, positive emotion experienced during the past week was assessed with six items (e.g., positive, pleasant; $M=3.69 ; S D=.79, \alpha=.64$ ), as well as negative emotion (e.g., negative, afraid; $M=1.93 ; S D=$ $.63, \alpha=.88)$. 
Depression and anxiety symptoms. We used the Brief Symptom Inventory [41] $(0=$ not at all, $4=$ very $\mathrm{much}$ ) to assess depression and anxiety symptoms experienced in the past week, which includes a six-item depression subscale (e.g., feeling blue, feeling hopeless about the future; $M=.57 ; S D=.61, \alpha=.84$ ) and a six-item anxiety subscale (e.g., feeling tense, feeling suddenly scared; $M=.59 ; S D=.67, \alpha=.90)$.

Loneliness. We assessed loneliness during the past week using a three-item Brief Loneliness Measure [42] ("How often have you felt that you lacked companionship?" How often have you felt left out?" "How often have you felt isolated from others?"; 1 = hardly ever, $3=$ often; $M=1.37 ; S D=.50, \alpha=.78)$.

Health behavior. We assessed health behavior by asking participants how many days over the past week (out of seven days) they engaged in six health-related activities and then summed the three healthy behaviors (engaging in aerobic physical activity for at least 15 minutes, engaging in strengthening exercises, and eating fruits or vegetables; $M=4.09 ; S D=1.45, \alpha=$ .65 ) and the three unhealthy behaviors (eating junk food, smoking cigarettes/cigars/electronic cigarettes/using chewing tobacco, and having three or more alcoholic beverages; $M=1.77 ; S D$ $=.92, \alpha=.48$ ).

Covariates. In addition to demographic characteristics (gender, age, level of education, sibling status, household income), we measured several uncertainty-relevant covariates, including dispositional optimism, intolerance of uncertainty, and satisfaction with life. We assessed dispositional optimism with the Life Orientation Test-Revised [43] (6 items after removing filler items; e.g., "In uncertain times, I usually expect the best," "I hardly ever expect things to go my way"; 1 = strongly disagree, $5=$ strongly agree; $M=3.80, S D=.66, \alpha=.80)$. We assessed intolerance of uncertainty with the 12-item Intolerance of Uncertainty-Short Form [44] (e.g., "Unforeseen events upset me greatly," "It frustrated me not having all the information I need"; 1 = not at all characteristic of me, 5 = extremely characteristic of me; $M=2.22, S D$ $=.66, \alpha=.87)$. Finally, we assessed satisfaction with life using the 5-item Satisfaction with Life Scale [45] (e.g., "In most ways my life is close to my ideal," "The conditions of my life are excellent"; 1 = strongly disagree, $5=$ strongly agree; $M=3.98, S D=1.14, \alpha=.83$ ). To provide the most conservative estimate of our effects, we included all available demographic variables, as well as the three individual difference measures just described (the only ones available in the dataset), as covariates in our analyses.

\section{Results}

We tested our hypotheses with multiple regression analyses predicting health and well-being from quarantine length, flow, mindfulness, and the interactions between quarantine length and flow/mindfulness. All variables were grand-mean centered. We controlled for gender, age, education, region, sibling status, family income, dispositional optimism, intolerance of uncertainty, and satisfaction with life in all analyses. Given the large sample size $(N=5115)$, we define statistical significance for our purposes as effects at $p<.01$. Table 2 presents bivariate correlations between our variables.

Table 3 presents the full regression results for each measure of health and well-being. Note that quarantine length was a significant predictor of all but one measure (positive emotion). In all but one case (healthy behavior), a longer quarantine was associated with poorer well-being.

\section{Flow}

Looking first at flow's overall association with well-being, the results were mixed (see Table 3 for key results; full results available on the Open Science Framework along with study materials). Participants who reported greater flow also reported more positive emotion, less severe 
Table 2. Bivariate correlations.

\begin{tabular}{|c|c|c|c|c|c|c|c|c|c|c|}
\hline & $\begin{array}{l}\text { Mindful- } \\
\text { ness }\end{array}$ & $\begin{array}{c}\text { Quarantine } \\
\text { length }\end{array}$ & Worry & $\begin{array}{l}\text { Negative } \\
\text { emotion }\end{array}$ & $\begin{array}{l}\text { Positive } \\
\text { emotion }\end{array}$ & $\begin{array}{l}\text { Depressive } \\
\text { symptoms }\end{array}$ & $\begin{array}{c}\text { Anxious } \\
\text { symptoms }\end{array}$ & $\begin{array}{l}\text { Loneli- } \\
\text { ness }\end{array}$ & $\begin{array}{c}\text { Healthy } \\
\text { behaviors }\end{array}$ & $\begin{array}{l}\text { Unhealthy } \\
\text { behaviors }\end{array}$ \\
\hline Flow & $.56^{*}$ & -.03 & -.02 & $-.16^{*}$ & $.46^{*}$ & $-.22^{*}$ & $-.14^{*}$ & $-.26^{*}$ & $.33^{*}$ & $-.16^{*}$ \\
\hline Mindfulness & & $.02^{*}$ & -.03 & $-.18^{*}$ & $.44^{*}$ & $-.19^{*}$ & $-.13^{*}$ & $-.12^{*}$ & $.26^{*}$ & $-.06^{*}$ \\
\hline $\begin{array}{l}\text { Quarantine } \\
\text { length }\end{array}$ & & & $.13^{*}$ & $.10^{*}$ & -.04 & $.14^{*}$ & $.12^{*}$ & $.16^{*}$ & .03 & $.10^{*}$ \\
\hline Worry & & & & $.34^{*}$ & -.03 & $.25^{*}$ & $.35^{*}$ & $.19^{*}$ & .007 & $.11^{*}$ \\
\hline $\begin{array}{l}\text { Negative } \\
\text { emotion }\end{array}$ & & & & & $-.29^{*}$ & $.62^{*}$ & $.66^{*}$ & $.34^{*}$ & $-.13^{*}$ & $.13^{*}$ \\
\hline $\begin{array}{l}\text { Positive } \\
\text { emotion }\end{array}$ & & & & & & $-.33^{*}$ & $-.24^{*}$ & $-.31^{*}$ & $.31^{*}$ & $-.17^{*}$ \\
\hline $\begin{array}{l}\text { Depressive } \\
\text { symptoms }\end{array}$ & & & & & & & $.73^{*}$ & $.43^{*}$ & $-.17^{*}$ & $.16^{*}$ \\
\hline $\begin{array}{l}\text { Anxious } \\
\text { symptoms }\end{array}$ & & & & & & & & $.35^{*}$ & $-.13^{*}$ & $.12^{*}$ \\
\hline Loneliness & & & & & & & & & $-.17^{*}$ & $.31^{*}$ \\
\hline $\begin{array}{l}\text { Healthy } \\
\text { behaviors }\end{array}$ & & & & & & & & & & $-.02^{*}$ \\
\hline
\end{tabular}

Note

$p<.01$.

https://doi.org/10.1371/journal.pone.0242043.t002

depressive symptoms, less loneliness, more healthy behaviors, and fewer unhealthy behaviors. However, interactions with quarantine length were more consistent. With the exception of positive emotion and healthy behaviors, flow significantly moderated the relationship between

Table 3. Keys results of multiple regression models.

\begin{tabular}{|c|c|c|c|c|c|}
\hline & Quarantine Length & Flow & Mindfulness & Flow x Quarantine Length & Mindfulness x Quarantine Length \\
\hline & $\beta\left[\mathrm{CI}_{95 \%}\right]$ & $\beta\left[C I_{95 \%}\right]$ & $\beta\left[C I_{95 \%}\right]$ & $\beta\left[C I_{95 \%}\right]$ & $\beta\left[C I_{95 \%}\right]$ \\
\hline \multirow[t]{2}{*}{ Worry } & $.10^{*}$ & .001 & -.03 & $-.04^{*}$ & .02 \\
\hline & {$[.07, .13]$} & {$[-.03, .03]$} & {$[-.06, .003]$} & {$[-.07,-.01]$} & {$[-.02, .06]$} \\
\hline \multirow[t]{2}{*}{ Negative emotion } & $.06^{*}$ & .004 & $-.09^{*}$ & $-.05^{*}$ & .01 \\
\hline & {$[.03, .08]$} & {$[-.03, .03]$} & {$[-.12,-.06]$} & {$[-.07,-.02]$} & {$[-.02, .05]$} \\
\hline \multirow{2}{*}{ Positive emotion } & -.02 & $.17^{*}$ & $.19^{*}$ & -.004 & -.02 \\
\hline & {$[-.04, .006]$} & {$[.14, .19]$} & {$[.16, .22]$} & {$[-.03, .02]$} & {$[-.05, .01]$} \\
\hline \multirow[t]{2}{*}{ Depressive symptoms } & $.09^{*}$ & $-.04^{*}$ & $-.06^{*}$ & $-.06^{*}$ & .01 \\
\hline & {$[.07, .11]$} & {$[-.06,-.01]$} & {$[-.08,-.03]$} & {$[-.09,-.04]$} & {$[-.01, .04]$} \\
\hline \multirow[t]{2}{*}{ Anxious symptoms } & $.07^{*}$ & -.004 & $-.05^{*}$ & $-.06^{*}$ & .03 \\
\hline & {$[.04, .09]$} & {$[-.03, .02]$} & {$[-.08,-.02]$} & {$[-.08,-.03]$} & {$[.0002, .06]$} \\
\hline \multirow[t]{2}{*}{ Loneliness } & $.12^{*}$ & $-.15^{*}$ & $.06^{*}$ & $-.05^{*}$ & .01 \\
\hline & {$[.10, .15]$} & {$[-.18,-.12]$} & {$[.03, .09]$} & {$[-.08,-.02]$} & {$[-.02, .05]$} \\
\hline \multirow[t]{2}{*}{ Healthy behaviors } & $.04^{*}$ & $.19^{*}$ & $.06^{*}$ & -.01 & .005 \\
\hline & {$[.01, .07]$} & {$[.16, .22]$} & {$[.03, .09]$} & {$[-.05, .02]$} & {$[-.03, .04]$} \\
\hline \multirow[t]{2}{*}{ Unhealthy behaviors } & $.08^{*}$ & $-.12^{*}$ & $.05^{*}$ & $-.05^{*}$ & .04 \\
\hline & {$[.05, .11]$} & {$[-.15,-.08]$} & {$[.01, .08]$} & {$[-.08,-.02]$} & {$[.001, .08]$} \\
\hline
\end{tabular}

Note

" $p<.01$. Estimates are from models that control for gender, age, sibling status, education, family income, dispositional optimism, intolerance of uncertainty, and satisfaction with life. ${ }^{\mathrm{a}} 1=0$ days, $2=1-7$ days, $3=7-14$ days, $4=$ more than 14 days.

https://doi.org/10.1371/journal.pone.0242043.t003 
quarantine length and all other measures of well-being. Table 4 presents the associations between quarantine length and well-being at +/-1 SD for flow. As hypothesized, these associations are quite robust for those who reported relatively little flow, whereas they weakened considerable (nearly disappearing in some cases) among those who reported relatively high levels of flow.

\section{Mindfulness}

As predicted, mindfulness was a consistent predictor of overall well-being. With the exception of worry (weak association) and unhealthy behavior (positive association), participants who reported experiencing more mindfulness reported better well-being. However, in contrast to flow, mindfulness did not significantly moderate the association between quarantine length and any measure of well-being.

\section{Alternative analyses}

Because of the majority of the sample was not yet in quarantine, we also ran models coding quarantine length as $-0.5=$ no quarantine $(n=3762),+0.5=14+$ days of quarantine $(n=934)$. The results were nearly identical, except that flow no longer significantly moderated the associations between loneliness and quarantine length (just below significance) or unhealthy behavior and quarantine length, and mindfulness no longer showed a significant association with loneliness (just below significance).

\section{Discussion}

This study provides a unique opportunity to understand the experiences of people at ground zero for a worldwide pandemic, nearly in real-time. As we write this paper in October 2020, COVID-19 has been nearly eradicated in China; however, the number of new cases in the U.S. continues to rise rapidly, and millions of people worldwide are currently in or will soon enter (or re-enter) some form of quarantine or isolation. As such, our findings provide timely guidance to those experiencing distress associated with quarantine conditions.

Specifically, the findings reveal three key insights about this unique and stressful experience, which may generalize to similar periods of open-ended uncertainty. First, people who had endured a longer quarantine reported poorer well-being by many definitions: more worry, more negative emotions, more depressive and anxious symptoms, more loneliness, and more unhealthy behaviors. Second, experiencing flow and mindfulness was associated with better

Table 4. Associations between quarantine length and well-being, modeled at +/-1 SD for flow.

\begin{tabular}{|c|c|c|}
\hline & -1 SD Flow & +1 SD Flow \\
\hline & $\boldsymbol{\beta}\left[\mathrm{CI}_{95 \%}\right]$ & $\boldsymbol{\beta}\left[\mathrm{CI}_{95 \%}\right]$ \\
\hline Worry & $.14^{*}[.10, .18]$ & $.06^{*}[.02, .10]$ \\
\hline Negative emotion & $.11^{*}[.07, .14]$ & $.007[-.03, .04]$ \\
\hline Depressive symptoms & $.16^{*}[.12, .19]$ & $.02[-.01, .06]$ \\
\hline Anxious symptoms & $.12 *[.09, .16]$ & $.01[-.02, .05]$ \\
\hline Loneliness & $.18^{*}[.14, .21]$ & $.07^{*}[.03, .11]$ \\
\hline Unhealthy behaviors & $.12 *[.08, .16]$ & $.05[.003, .09]$ \\
\hline
\end{tabular}

https://doi.org/10.1371/journal.pone.0242043.t004 
well-being during the stressful circumstances in which people found themselves in China in February 2020, regardless of quarantine status or length. Comparing effect sizes in Table 1, flow seemed particularly associated with reduced loneliness, engagement in healthy behaviors, and avoidance of unhealthy behaviors, whereas mindfulness was more associated with fewer negative emotions and anxious symptoms-although mindfulness was also associated with greater loneliness and more unhealthy behavior. Flow and mindfulness were approximately equally associated with elevated positive emotions and reduced depressive symptoms.

Third, and perhaps most novel, flow-but not mindfulness-moderated the link between quarantine length and well-being deficits. In fact, people in a lengthy quarantine who reported higher-than-average flow experiences in the past week (i.e., $+1 \mathrm{SD}$ ) were no worse off than people who were not yet quarantined on many measures of well-being, statistically speaking (see Table 2). Length of quarantine remained significantly associated with worry and loneliness among those high in flow (albeit a far weaker association compared to those low in flow), which suggests the possibility that worry and loneliness may be particularly stubborn forms of distress during quarantine. In contrast, mindfulness did not moderate any link between quarantine length or status and well-being.

Why did flow so consistently moderate what appear to be deleterious effects of quarantine length - and equally important, why did mindfulness not? In short, flow is a form of exquisite distraction, perfect for situations in which the primary goal is to make time pass more quickly $[12,46]$. As a quarantine wears on, people may find that the tedium of isolation allows their worries to run wild, with little else to keep their mind occupied. If instead people can find activities that absorb their attention, the days feel shorter and the weeks, therefore, more tolerable. Of course, it is likely that not all forms of distraction are so consistently beneficial to wellbeing; for example, if a problem needs to be addressed or emotions processed, distraction may be detrimental to well-being in the long-run. However, flow is a particularly beneficial form of distraction, perhaps because it entails active engagement rather than avoidance or suppression.

Mindfulness, on the other hand, draws attention toward one's present circumstances and internal states. As in daily life, our findings suggest that mindfulness is good for reducing distress in a given moment or on a given day during a widespread health crisis. However, mindfulness is nearly antithetical to distraction (in fact, a reverse-coded item on the scale used in this study is "I have been easily distracted"), and flow-inducing distractions may be the very best medicine to bolster well-being during a lengthy quarantine.

We would note that although we asked participants to reflect on their experiences of mindfulness and flow during the previous week, the measure likely tapped into both state and trait aspects of these variables. That is, a person who reported a high degree of mindfulness during the past week is likely also someone who is dispositionally mindful. We attempted to mitigate the influence of dispositional characteristics by controlling for conceptually-related individual differences, namely dispositional optimism, intolerance of uncertainty, and satisfaction with life. Nonetheless, our findings may also point to well-being advantages among those naturally disposed toward mindfulness and flow.

Although our study had a number of strengths, most notably the large sample size and the timely, highly significant real-world context, several weaknesses are worth noting. The study was cross-sectional, thus rendering our data incapable of testing causal hypotheses. We argue that our interpretation of the direction of effects is the most parsimonious, given our efforts to control for likely third variables and the well-established causal links between flow/mindfulness and well-being in other contexts. However, it is possible that some relationships are reciprocal, such that experiencing distress disrupts people's ability to find flow and remain mindful, or that we failed to assess relevant third variables. Similarly, it is possible that people who were 
more distressed opted into quarantine (i.e., reverse causality) rather than quarantine conditions causing deterioration of well-being. We propose that the most parsimonious explanation is a deleterious effect of isolation and restricted movement, particularly given other research that found such effects in other pandemics [e.g., 2, 4] and in the current pandemic [in France; 5] and given the relatively strict policies regarding quarantine during that period in China, quite different from the United States and other countries with more lenient policies. That said, quarantine status was almost certainly a function of where our participants lived within China, thus introducing the possibility of third-variable explanations in those associations as well.

In addition, we would note that a large majority of our sample was not (yet) in quarantine at the time they completed the survey, although presumably all of our participants were keenly aware of the growing health crisis in their country and experienced significant disruptions to their lives. Ideally, we would have followed participants longitudinally as they passed in and out of quarantine restrictions, or at least had more even coverage across various lengths of quarantine. Furthermore, our sample was skewed toward relatively educated participants (nearly all had a Bachelor's degree), given the nature of the data collection strategy.

Another unavoidable feature of our sample was the relatively short average length of quarantine (weeks rather than months). Our study cannot address the usefulness of flow and mindfulness across longer periods of distancing and isolation like those that are now the norm in the United States and other countries. On the other hand, our study is well-suited to address a particular type of isolation that remains common, namely the more extreme quarantine recommendations following potential exposure to someone with COVID-19 or a positive test for the virus. Our findings may be most helpful to people in these relatively short, time-limited, and highly restrictive conditions.

Finally, we were limited in the length of our survey by practical constraints, and thus we do not have information about the activities that most effectively or consistently promoted flow states. Other studies have found that although people seem capable of reporting on their flow states, they are less successful at identifying activities that are particularly flow-inducing [12]. Although flow activities are highly idiosyncratic, activities that provide the right level of challenge (not too hard, not too easy) and offer feedback on one's progress are most reliable at creating flow states [6]. A key direction for future research is to more clearly identify the types of activities that work best for the most people, as well as examining the importance of personactivity fit, during periods of quarantine-like conditions.

Despite these limitations, this study offers a rare glimpse inside a community at the initial epicenter of a once-in-a-century pandemic. At the time the data were collected, Wuhan was unique in its strict restrictions and widespread lockdown. In the relatively brief time since then, the crisis has grown and spread exponentially, such that people across the world are experiencing conditions like those of our participants. Our findings provide a glimmer of hope for people struggling with the challenges of social distancing or even complete quarantine: The time may pass more quickly if you find your flow.

\section{Author Contributions}

Conceptualization: Kate Sweeny.

Data curation: Xiaorong Cheng, Lulu Hou, Fangfang Long, Yao Meng, Lilian Azer, Weiwei Zhang.

Formal analysis: Kate Sweeny.

Methodology: Kate Sweeny, Lilian Azer, Renlai Zhou, Weiwei Zhang. 
Project administration: Xiaorong Cheng, Lulu Hou, Fangfang Long, Yao Meng.

Supervision: Renlai Zhou, Weiwei Zhang.

Writing - original draft: Kate Sweeny, Kyla Rankin.

Writing - review \& editing: Kate Sweeny, Kyla Rankin, Weiwei Zhang.

\section{References}

1. Brooks SK, Webster RK, Smith LE, Woodland L, Wessely S, Greenberg N, et al. The psychological impact of quarantine and how to reduce it: rapid review of the evidence. The Lancet. 2020 Feb 26.

2. Hawryluck L, Gold WL, Robinson S, Pogorski S, Galea S, Styra R. SARS control and psychological effects of quarantine, Toronto, Canada. Emerg Infect Dis. 2004 Jul; 10(7): 1206-1212. https://doi.org/ 10.3201/eid1007.030703 PMID: 15324539

3. Reynolds DL, Garay JR, Deamond SL, Moran MK, Gold W, Styra R. Understanding, compliance and psychological impact of the SARS quarantine experience. Epidemiol Infect. 2008 Jul; 136(7): 9971007. https://doi.org/10.1017/S0950268807009156 PMID: 17662167

4. Marjanovic Z, Greenglass ER, Coffey S. The relevance of psychosocial variables and working conditions in predicting nurses' coping strategies during the SARS crisis: an online questionnaire survey. Int J Nurs Stud. 2007 Aug 1; 44(6):991-998. https://doi.org/10.1016/j.jpurstu.2006.02.012 PMID: 16618485

5. Droit-Volet Sylvie, et al. Time and Covid-19 stress in the lockdown situation: Time free, «Dying» of boredom and sadness. PloS one. 2020 August 10; 15(8): e0236465. https://doi.org/10.1371/journal.pone. 0236465 PMID: 32776990

6. Flow Csikszentmihalyi M. The Psychology of Optimal Experience. New York (HarperPerennial); 1990.

7. Eisenberger R, Jones JR, Stinglhamber F, Shanock L, Randall AT. Flow experiences at work: For high need achievers alone?. J Organ Behav. 2005 Nov; 26(7): 755-75.

8. Fullagar CJ, Kelloway EK. Flow at work: An experience sampling approach. J Occup Organ Psychol. 2009 Sep; 82(3): 595-615.

9. Jackson SA, Ford SK, Kimiecik JC, Marsh HW. Psychological correlates of flow in sport. J Sport Exerc Psychol. 1998 Dec 1; 20(4): 358-78.

10. Zumeta L, Basabe N, Wlodarczyk A, Bobowik M, Páez D. Shared flow and positive collective gatherings. Anales de Psicología. 2016; 32(3):717-727.

11. Isham A, Gatersleben B, Jackson T. Flow activities as a route to living well with less. Environ Behav. 2019 May; 51(4): 431-461.

12. Rankin K, Walsh LC, Sweeny K. A better distraction: Exploring the benefits of flow during uncertain waiting periods. Emotion. 2019 Aug; 19(5): 818-828. https://doi.org/10.1037/emo0000479 PMID: 30265082

13. Asakawa K. Flow experience and autotelic personality in Japanese college students: How do they experience challenges in daily life?. J Happiness Stud. 2004 Jun 1; 5(2): 123-54.

14. Asakawa K. Flow experience, culture, and well-being: How do autotelic Japanese college students feel, behave, and think in their daily lives?. J Happiness Stud. 2010 Apr 1; 11(2): 205-23.

15. Brom C, Šisler V, Slussareff M, Selmbacherová T, Hlávka Z. You like it, you learn it: affectivity and learning in competitive social role play gaming. Int J Comput Support Collab Learn. 2016 July 29; 11(3): 313-348.

16. Ho HC, Mui M, Wan A, Stewart SM, Yew C, Lam TH, et al. Happy Family Kitchen: Behavioral outcomes of a brief community-based family intervention in Hong Kong. J Child Fam Stud. 2017 Oct 1; 26(10): 2852-64.

17. Mosing MA, Butkovic A, Ullen F. Can flow experiences be protective of work-related depressive symptoms and burnout? A genetically informative approach. J Affect Disord. 2018 Jan 15; 226: 6-11. https:// doi.org/10.1016/j.jad.2017.09.017 PMID: 28942204

18. Bassi M, Steca P, Monzani D, Greco A, Delle Fave A. Personality and optimal experience in adolescence: Implications for well-being and development. J Happiness Stud. 2014 Aug 1; 15(4): 829-43.

19. Martin JR. Mindfulness: A proposed common factor. J Psychother Integr. 1997 Dec 1; 7(4):291-312.

20. Batchelor S. The awakening of the West: the encounter of Buddhism and Western culture, $542 \mathrm{BC}$ 1992. 
21. Brown KW, Ryan RM. The benefits of being present: mindfulness and its role in psychological wellbeing. J Pers Soc Psychol. 2003 Apr; 84(4): 822-848. https://doi.org/10.1037/0022-3514.84.4.822 PMID: 12703651

22. Brown KW, Ryan RM, Creswell JD. Mindfulness: Theoretical foundations and evidence for its salutary effects. Psychological inquiry. 2007 Oct 19; 18(4):211-37.

23. Kabat-Zinn J. Mindfulness-based interventions in context: past, present, and future. Clinical psychology: Science and practice. 2003 Jun; 10(2):144-56.

24. Shapiro SL, Carlson LE, Astin JA, Freedman B. Mechanisms of mindfulness. J Clin Psychol. 2006 Mar; 62(3): 373-386. https://doi.org/10.1002/jclp.20237 PMID: 16385481

25. Coffey KA, Hartman M. Mechanisms of action in the inverse relationship between mindfulness and psychological distress. Complement Health Pract Rev. 2008 Apr; 13(2): 79-91.

26. Hanley AW, Garland EL. Dispositional mindfulness co-varies with self-reported positive reappraisal. Pers Individ Diff. 2014 Aug 1; 66:146-52. https://doi.org/10.1016/j.paid.2014.03.014 PMID: 24904191

27. Sedlmeier P, Eberth J, Schwarz M, Zimmermann D, Haarig F, Jaeger S, et al. The psychological effects of meditation: a meta-analysis. Psychol Bull. 2012 Nov; 138(6): 1139-1171. https://doi.org/10.1037/ a0028168 PMID: 22582738

28. Sweeny K, Howell JL. Bracing later and coping better: Benefits of mindfulness during a stressful waiting period. Pers Soc Psychol Bull. 2017 Oct; 43(10):1399-414. https://doi.org/10.1177/ 0146167217713490 PMID: 28918715

29. Keller J, Ringelhan S, Blomann F. Does skills-demands compatibility result in intrinsic motivation? Experimental test of a basic notion proposed in the theory of flow-experiences. J Posit Psychol. 2011 Sep 1; 6(5):408-417.

30. Rogatko TP. The influence of flow on positive affect in college students. J Happiness Stud. 2009 Apr 1 ; 10(2): 133-148.

31. Garland EL, Hanley A, Farb NA, Froeliger B. State mindfulness during meditation predicts enhanced cognitive reappraisal. Mindfulness. 2015 Apr 1; 6(2): 234-242. https://doi.org/10.1007/s12671-0130250-6 PMID: 26085851

32. Hawley LL, Schwartz D, Bieling PJ, Irving J, Corcoran K, Farb NA, et al. Mindfulness practice, rumination and clinical outcome in mindfulness-based treatment. Cognit Ther Res. 2014 Feb 1; 38(1): 1-9.

33. Mindfulness Reid D. and flow in occupational engagement: Presence in doing. Can J Occup Threr. 2011 Feb; 78(1): 50-56. https://doi.org/10.2182/cjot.2011.78.1.7 PMID: 21395198

34. Sheldon KM, Prentice M, Halusic M. The experiential incompatibility of mindfulness and flow absorption. Social Psychological and Personality Science. 2015 Apr; 6(3):276-83.

35. Layous K, Nelson SK, Lyubomirsky S. What is the optimal way to deliver a positive activity intervention? The case of writing about one's best possible selves. J Happiness Stud. 2013 Apr 1; 14(2):635-654.

36. Nelson SK, Fuller JA, Choi I, Lyubomirsky S. Beyond self-protection: Self-affirmation benefits hedonic and eudaimonic well-being. Pers Soc Psychol Bull. 2014 Aug; 40(8): 998-1011. https://doi.org/10.1177/ 0146167214533389 PMID: 24781897

37. Feldman G, Hayes A, Kumar S, Greeson J, Laurenceau JP. Mindfulness and emotion regulation: The development and initial validation of the Cognitive and Affective Mindfulness Scale-Revised (CAMS-R). Journal of psychopathology and Behavioral Assessment. 2007 Sep 1; 29(3):177.

38. Chan HL, Lo LY, Lin M, Thompson N. Revalidation of the cognitive and affective mindfulness scaleRevised (CAMS-R) with its newly developed Chinese version (Ch-CAMS-R). J Pacific Rim Psych 2016; 10.

39. McCaul KD, Goetz PW. Worry. National Center Institute Deivision of Cancer Control and Population Sciences. n.d. [Cited 2020 March 16]. Available from: https://cancercontrol.cancer.gov/brp/research/ constructs/worry.html

40. Diener E, Wirtz D, Biswas-Diener R, Tov W, Kim-Prieto C, Choi DW, et al. New measures of well-being Springer, Dordrecht. In: Assessing well-being; 2009 pp. 247-266.

41. Derogatis LR, Fitzpatrick M. The SCL-90-R, the Brief Symptom Inventory (BSI), and the BSI-18. Lawrence Erlbaum Associates Publishers; 2004.

42. Hughes ME, Waite LJ, Hawkley LC, Cacioppo JT. A short scale for measuring loneliness in large surveys: Results from two population-based studies. Res Aging. 2004 Nov; 26(6): 655-672.

43. Scheier MF, Carver CS, Bridges MW. Distinguishing optimism from neuroticism (and trait anxiety, selfmastery, and self-esteem): a reevaluation of the Life Orientation Test. J pers Soc Psychol. 1994 Dec; 67(6): 1063-1078. 
44. Carleton RN, Norton MP, Asmundson GJ. Fearing the unknown: A short version of the Intolerance of Uncertainty Scale. J Anxiety Disord. 2007 Jan 1; 21(1): 105-17. https://doi.org/10.1016/j.janxdis.2006. 03.014 PMID: 16647833

45. Diener ED, Emmons RA, Larsen RJ, Griffin S. The satisfaction with life scale. J Pers Assess. 1985 Feb 1; 49(1): 71-5. https://doi.org/10.1207/s15327752jpa4901_13 PMID: 16367493

46. Rankin K, Sweeny K, Xu S. Associations between subjective time perception and well-being during stressful waiting periods. Stress Health. 2019 Oct; 35(4): 549-559. https://doi.org/10.1002/smi.2888 PMID: 31373429 